\title{
Asymptomatic Pneumothorax Mimicking Pseudoaneurysm after the Implantation of a Dual-Chamber Pacemaker
}

\author{
Tolga Aksu, Tumer Erdem Guler, Serdar Bozyel \\ Department of Cardiology, University of Health Sciences, Kocaeli Derince Training and Research Hospital, Kocaeli, Turkey \\ ORCID: \\ Tolga Aksu: https://orcid.org/0000-0001-8061-9660 \\ Tümer Erdem Güler: https://orcid.org/0000-0003-1349-2123 \\ Serdar Bozyel: https://orcid.org/0000-0002-6582-3660
}

\section{Abstract}

An 80-year-old male, who had undergone dual-chamber pacemaker implantation through left subclavian approach, developed tension pneumothorax of the left side. It caused a pseudoaneurysm-like contracting mass image on the chest X-ray. The diagnosis of pneumothorax was verified by chest computed tomography. Tube thoracostomy drainage was performed immediately without any sequel.

Keywords: Cardiac pacing, cephalic vein cutdown, complication, subclavian puncture, venous access

\section{INTRODUCTION}

An increase in the frequency of cardiac rhythm management device (CRMD) implantations has also led to an increase in device-related complications, in hospitalization period, and treatment costs. ${ }^{[1-3]}$ Pneumothorax is a relatively mild complication during CRMD implantation using the subclavian puncture technique. However, the incidence of pneumothorax requiring a chest tube may be as high as $0.66 \%$ even in experienced centers. ${ }^{[2]}$

\section{Case Report}

An 80-year-old male was referred to our clinic with a 2-month history of progressive fatigue and presyncope episodes. An electrocardiogram showed third-degree heart block with a pulse rate of 36 beats per minute. There was no identifiable and reversible cause of heart block. Thus, he was scheduled for a permanent pacemaker insertion. The atrial and ventricular leads were inserted via the puncture of the left subclavian vein. The right ventricular bipolar screw-in lead (St. Jude Medical Tendril MRITM) was positioned against the right ventricle apex. The right atrial bipolar passive lead (St. Jude Medical Isoflex MRITM) was positioned at the

Submission: 25-Apr-18 Accepted: 02-Aug-18
Access this article online
Quick Response Code:

anterolateral wall of the right atrium. Lead sensing, pacing threshold, and pacing impedance of both right atrial and ventricular leads were within the expected normal ranges (the right atrium lead: pacing threshold, $1.5 \mathrm{~V} / 0.4 \mathrm{~ms}$; sensing threshold, $3 \mathrm{mV}$; lead impedance, $550 \Omega$ and the right ventricle lead: pacing threshold, $0.5 \mathrm{~V} / 0.4 \mathrm{~ms}$; sensing threshold, $13 \mathrm{mV}$; and lead impedance, $650 \Omega$ ). The chest fluoroscopic imaging performed immediately after the procedure revealed pseudoaneurysm-like bulging at the left ventricular apical site [Figure 1]. The site was contracting together with the heart beat. The patient had no chest pain or shortness of breath. A computed tomography scan was scheduled. A left-sided pneumothorax and slight mediastinal shift to the right were detected on the computed tomography [Figures 2 and 3]. A chest tube with underwater seal drainage was inserted according to the recommendation of chest surgeon. Control chest X-ray demonstrated complete resolution of pneumothorax. The chest tube was removed on the $3^{\text {rd }}$ day of hospitalization.

Address for correspondence: Prof. Tolga Aksu, Department of Cardiology, University of Health Sciences, Kocaeli Derince Training and Research Hospital, Kocaeli, Turkey. E-mail: aksutolga@gmail.com

This is an open access journal, and articles are distributed under the terms of the Creative Commons Attribution-NonCommercial-ShareAlike 4.0 License, which allows others to remix, tweak, and build upon the work non-commercially, as long as appropriate credit is given and the new creations are licensed under the identical terms.

For reprints contact: reprints@medknow.com

How to cite this article: Aksu T, Guler TE, Bozyel S. Asymptomatic pneumothorax mimicking pseudoaneurysm after the implantation of a dual-chamber pacemaker. Int J Cardiovasc Acad 2019;5:15-7. 


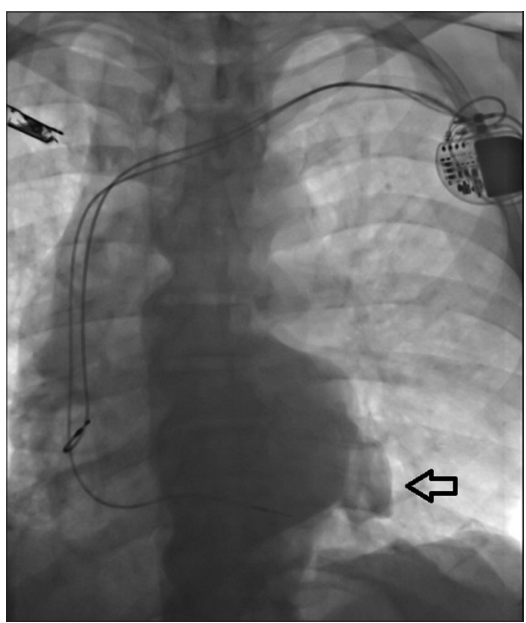

Figure 1: Radiographic findings of a fluoroscopy revealed a left-sided pneumothorax with a pseudoaneurysm-like bulging at the left ventricular apical site (black arrow)

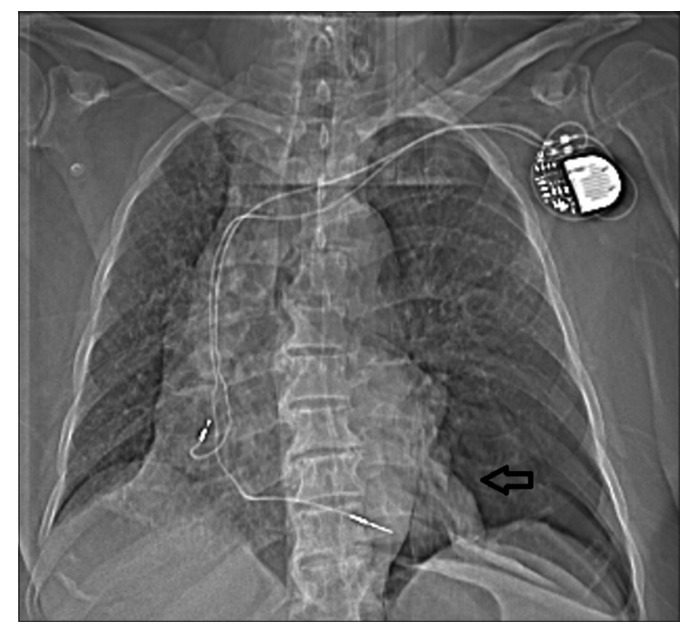

Figure 2: Radiographic findings of a computed tomography in the frontal plane revealed a left-sided pneumothorax with a pseudoaneurysm-like bulging at the left ventricular apical site (black arrow)

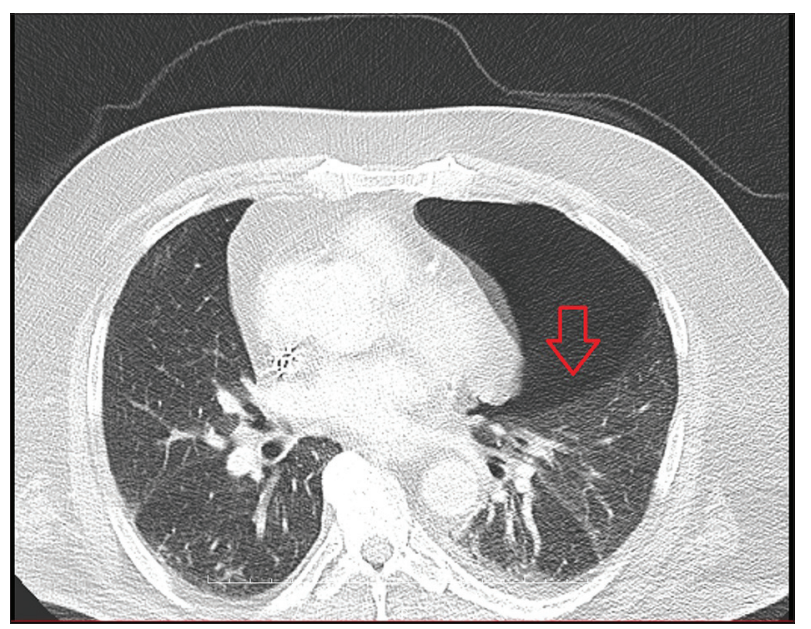

Figure 3: Radiographic findings of a computed tomography in the horizontal plane revealed a left-sided pneumothorax. Please note that the lung tissue is sliding to the posterior side (red arrow)

\section{Discussion}

The incidence of pneumothorax after CRMD implantation by using subclavian vein access varies from $0.6 \%$ to $5.2 \%$ with an average of $2 \% \cdot{ }^{[4]}$ The most important precipitating factor is blindly punctured subclavian vein access. A detailed physical examination and anteroposterior chest radiography in standing position should be the first two steps in the assessment of patients demonstrating pneumothorax-related complaints such as chest pain and dyspnea because they are simple, inexpensive, rapid, and noninvasive. However, it should be kept in mind that some forms of pneumothorax may be asymptomatic as in our case. In order to not miss a possible pneumothorax complication in such cases, detailed evaluation of the postprocedural scopical views is of great importance. Chest computed tomography scanning is more sensitive than chest radiography in detecting a small pneumothorax.$^{[5]}$ In addition, computed tomography may be used to differentiate pneumothorax than other possible device-related complications. In the present case, the chest X-ray demonstrated a large left-sided pneumothorax, compressing the left lung and resembling a mass. As a unique nature of the mass, it was contracting together with heart like a pseudoaneurysm. Furthermore, the patient had no complaint of difficulty in breathing after implantation. Hence, we decided to perform chest computed tomography for differential diagnosis.

After proper diagnosis, treatment for pneumothorax varies from simple oxygenation to chest tube drainage. If a tension pneumothorax develops, urgent treatment with a chest tube is necessary. At this point, another important issue is that tension pneumothorax may alter lead-related parameters due to mechanical displacement of the leads by shifting of the mediastinum and may require a lead revision procedure. Thus, to check all lead-related parameters seems as reasonable after such a complication. In our case, there was no change on lead-related parameters. Use of venography or ultrasound to visualize the subclavian veins or the cephalic vein cutdown technique should be considered to avoid this complication in selected patients.

\section{ConcLusion}

Pneumothorax is a relatively common complication of CRMD implantation using the subclavian puncture technique. Early clinical doubt, well-performed physical examination, and truly used imaging methods are cornerstone for early and true diagnosis.

\section{Declaration of patient consent}

The authors certify that they have obtained all appropriate patient consent forms. In the form the patient(s) has/have given his/her/their consent for his/her/their images and other clinical information to be reported in the journal. The patients understand that their names and initials will not be published and due efforts will be made to conceal their identity, but anonymity cannot be guaranteed. 


\section{Financial support and sponsorship}

Nil.

\section{Conflicts of interest}

There are no conflicts of interest.

\section{RefEREnCes}

1. Palmisano P, Accogli M, Zaccaria M, Luzzi G, Nacci F, Anaclerio M, et al. Rate, causes, and impact on patient outcome of implantable device complications requiring surgical revision: Large population survey from two centres in İtaly. Europace 2013;15:531-40.
2. Kirkfeldt RE, Johansen JB, Nohr EA, Moller M, Arnsbo P, Nielsen JC. Pneumothorax in cardiac pacing: A population-based cohort study of 28,860 Danish patients. Europace 2012;14:1132-8.

3. Pakarinen S, Oikarinen L, Toivonen L. Short-term implantation-related complications of cardiac rhythm management device therapy: A retrospective single-centre 1-year survey. Europace 2010;12:103-8.

4. Res JC, de Priester JA, van Lier AA, van Engelen CL, Bronzwaer PN, Tan $\mathrm{PH}$, et al. Pneumothorax resulting from subclavian puncture: A complication of permanent pacemaker lead implantation. Neth Heart J 2004; 12:101-5.

5. Zarogoulidis P, Kioumis I, Pitsiou G, Porpodis K, Lampaki S Papaiwannou A, et al. Pneumothorax: From definition to diagnosis and treatment. J Thorac Dis 2014;6:S372-6. 